\title{
El diálogo intertextual entre Las Argonáuticas de Apolonio de Rodas y las epopeyas homéricas
}

\author{
The intertextual dialogue between Apollonius Rhodius' Argonautica and the Homeric epic \\ Aluned Moreno del Cristo ${ }^{1}$
}

Fecha de recepción: 3-02-2020

Fecha de aceptación: 13-11-2019

\begin{abstract}
Resumen
Apolonio de Rodas fue uno de los principales representantes de la poesía griega del período helenístico. En su única obra conservada, Las Argonáuticas, este autor estableció un significativo diálogo con la tradición literaria anterior, especialmente con las epopeyas homéricas. Debido a la desatención que durante mucho tiempo existió con respecto a la literatura helenística, así como a la ausencia de un estudio integrador acerca de la obra de Apolonio en relación con sus antecedentes épicos, este trabajo se propuso realizar un análisis de la intertextualidad (particularmente la hipertextualidad) entre Las Argonáuticas y los poemas de Homero. Los aspectos examinados permitieron concluir que el poeta helenístico conjugó en su epopeya elementos de tradición y de innovación, y estableció un creativo diálogo intertextual con el antiguo aedo, pues a la vez que asimiló magistralmente los principales recursos y motivos de la épica tradicional, incorporó características estéticas propias de su tiempo.

Palabras clave: Argonáuticas, épica homérica, intertextualidad, poesía helenística, Apolonio de Rodas.
\end{abstract}

\begin{abstract}
Apollonius Rhodius was one of the main figures of the Greek poetry in the Hellenistic period. In his only remaining work, Argonautica, this author established a significant dialogue with the previous literary tradition, especially with the Homeric epic. Due to the fact that, for many years, the study of Hellenistic literature has been neglected, and that, in addition, there has never been a comprehensive account of the relationship between Apollonius' work and its epic antecedents, the purpose of this paper was to analyze intertextuality (specifically hipertextuality) between Argonautica and Homer's poems. The examined aspects led to the conclusion that the Hellenistic poet conjugated within his work elements of tradition and innovation, and established a creative intertextual dialogue with the ancient oral poet, since at the same time that he assimilated masterfully the main methods and motives of traditional epic, he also incorporated the aesthetic devices of his own time.
\end{abstract}

Keywords: Argonautica; Homeric epic; intertextuality; Hellenistic poetry, Apollonius Rhodius.

1 Licenciada en Letras, Universidad de La Habana. La Habana, Cuba. Correo electrónico: alunedmoreno@gmail.com 


\section{Introducción}

Durante el período helenístico, la literatura griega comenzó a regirse por nuevos presupuestos. La poesía de esta etapa, cultivada principalmente durante el siglo III a.C. en la ciudad de Alejandría, uno de los centros más importantes de la época, adquirió características diferentes, que suponían la búsqueda de perfección formal y lingüística, el empleo del humor y de la ironía, la variación y la novedad respecto a los modelos precedentes, el gusto por las composiciones breves y una vasta erudición literaria ${ }^{2}$.

Uno de los principales exponentes de la poesía alejandrina fue el erudito y filólogo griego Apolonio de Rodas (295/290215 a.C.). Alejándose de las tendencias predominantes en su tiempo, las cuales suponían en su mayor parte un distanciamiento con respecto a los poemas épicos de gran extensión a la manera de Homero, y la adopción de brevedad y densidad en la expresión, Apolonio prefirió las extensas epopeyas. De esta manera, su mayor obra y la única conservada hasta estos días, Las Argonáuticas, constituye un largo poema épico en cuatro libros (aunque ciertamente no tan extenso como las obras homéricas), que retoma y desarrolla como tema central el viaje de Jasón y los Argonautas hacia la Cólquide en busca del vellocino de oro, así como el regreso de la expedición a Grecia.

Apolonio no solo tuvo una gran relevancia en la literatura de su tiempo, sino que también influyó notablemente en el desarrollo posterior del género épico. Su epopeya sirvió como fuente de inspiración para la creación de una de las obras más importantes de la literatura clásica: La Eneida de Virgilio. Apolonio estableció asimismo significativos diálogos con la tradición literaria anterior, especialmente con la épica, representada por Homero (la Ilíada y la Odisea), y con la tragedia ática, en este caso específicamente con la Medea de Eurípides.

Precisamente en el período helenístico, los estudios filológicos acerca de la tradición literaria precedente (y particularmente de Homero) se desarrollaron de modo notable con la labor desempeñada por los eruditos en la Biblioteca de Alejandría. Apolonio, que fue el segundo director de la Biblioteca y se dedicó asimismo a la realización de trabajos filológicos (que lamentablemente no se han conservado), mostró un amplio conocimiento acerca de las obras homéricas en su poema épico, el cual manifiesta de manera evidente su filiación con las epopeyas de Homero, tanto a nivel formal (por el empleo del hexámetro, del lenguaje homérico y de diversos recursos también utilizados por el aedo), como en el plano del contenido, pues el autor alejandrino toma como modelos muchos de los pasajes de la Ilíada y la Odisea para crear los suyos ${ }^{3}$.

A pesar de la importancia de la epopeya de Apolonio y de su valor literario intrínseco, fue desatendida por la crítica durante mucho tiempo. Es sobre todo a partir de la segunda mitad del siglo XX que la literatura helenística en general y la obra de Apolonio en particular, comienzan a ser objeto de atención de los estudiosos. Desde entonces se han reevaluado diversos aspectos de la poética del autor alejandrino ${ }^{4}$; sin embargo, a pesar de los estudios críticos que ya se han efectuado, no se ha hallado ninguno que se dedique a analizar de forma sistemática e integradora la intertextualidad entre Las Argonáuticas de Apolonio y las obras homéricas. Así pues, en este trabajo se propone precisamente examinar el diálogo intertextual ${ }^{5}$ que se establece entre estos poemas, con el fin de valorar cabalmente la asimilación que realiza Apolonio de Rodas

2 Cf. Prólogo de Máximo Brioso en su edición de Las Argonáuticas de Apolonio de Rodas (2003, p. 11).

3 Ver Easterling, P. E. y Knox, B. M. W. (1990, pp. 632-644).

4 Como su impronta en la renovación del arte narrativo, en la conformación psicológica de los personajes, etcétera. Cf. Körte, A. y Händel, P. (1973, pp. 157-166).

5 Se entiende por intertextualidad, en sentido general, las relaciones que pueden hallarse "entre textos", en nuestro caso específicamente entre las obras literarias que serán analizadas. Sobre este concepto, $c f$. Kristeva, J. (1997, pp. 1-24). Por otro lado, se considera la hipertextualidad como una categoría contenida dentro del concepto más amplio de intertextualidad. Según la definición de Genette, la hipertextualidad es "toda relación que una un texto B (hipertexto) a un texto anterior A (hipotexto)”. Ver Genette, G. (1997, p. 57). 
de los principales recursos épicos, de acuerdo con las características de su época y sus propios intereses. Para ello, el trabajo se centrará fundamentalmente en la relación hipertextual, la cual permitirá ahondar en la interpretación de Las Argonáuticas y sus nexos con los paradigmas literarios de los que parte.

\section{Hipertextualidad}

Existe una relación de hipertextualidad, según es concebida por Gérard Genette, entre los poemas homéricos y Las Argonáuticas de Apolonio de Rodas. Esta última obra vendría a ser un hipertexto de los textos de Homero (hipotextos), y resulta de estos a partir de un proceso de transformación indirecto y complejo (imitación), puesto que, siguiendo los términos empleados por el propio Genette (1997, p. 57-58), Apolonio no "transpone", de manera general, la acción de las epopeyas homéricas, sino que cuenta algo diferente basándose precisamente en el modelo establecido por el aedo griego. Sin embargo, la relación hipertextual que se establece entre estas obras tiene la peculiaridad de que, a pesar de que Las Argonáuticas se derive de las epopeyas homéricas a partir de dicha transformación indirecta, (lo cual puede apreciarse sobre todo a través de los numerosos paralelismos que se emplean) en ciertos pasajes se puede percibir también que Apolonio realiza una transformación directa de algunos de los episodios de Homero, transponiendo a su obra acciones, lugares y personajes pertenecientes a los poemas homéricos. Por tanto, se puede hablar de la existencia tanto de paralelismos como de transposiciones dentro de la relación de hipertextualidad que se manifiesta entre las obras analizadas.

\subsection{Paralelismos}

En Las Argonáuticas se encuentran numerosos paralelismos, tanto en el plano del contenido como en el de la forma con las obras homéricas. Es evidente el hecho de que Apolonio conoce cabalmente el modelo que imita. Como se plantea en La poesía helenística: "Apolonio desea siempre que se le mida en relación con la antigua épica, especialmente con Homero" (Körte y Händel, 1973, p. 115).
Desde el inicio del libro I, el poeta helenístico establece un nexo con la tradición épica al referir el catálogo de los héroes que se sumaron a la expedición de Jasón (Arg., I, v.25-228), lo cual tiene su paralelo más inmediato y patente en el "Catálogo de las naves" del canto II de la Ilíada (v.494-759). Ambos catálogos inician con la invocación a las Musas, convención genérica con la que se pretende dar verosimilitud a lo que se va a referir, pues la empresa narrativa que se propone el poeta es ardua, más propia de las deidades que de los mortales. Existen sin embargo diferencias entre estos catálogos, pues mientras que Homero da a conocer el número de naves y los nombres de los jefes principales de cada una de las regiones griegas, Apolonio se detiene con mayor énfasis en los rasgos particulares que distinguen a cada uno de los héroes que han acudido al llamado de Jasón, y en las motivaciones que influenciaron a cada uno de ellos a tomar parte en la expedición. Se aprecia en Apolonio por tanto una mayor centralización en la individualidad heroica.

Además, como se ha señalado en "La épica helenística" de Luis Gil Fernández (2007, p. 247), el catálogo de Apolonio tiene una funcionalidad bien definida, pues constituye una parte significativa de la acción y se convierte en un prólogo necesario para lo que posteriormente se narrará en la obra. Por otra parte, es posible afirmar que no sucede lo mismo con el catálogo homérico, cuya función en el lugar del poema donde se encuentra es dudosa, y ha suscitado numerosas polémicas entre los especialistas acerca de su autenticidad. Algunos estudiosos, como Körte y Händel (1973, p. 117), plantean asimismo que se puede hallar una mayor variedad de recursos en la presentación que hace Apolonio de su catálogo, mientras que Homero solo emplea un número reducido de fórmulas para dar a conocer a las tropas aqueas. Esto, sin embargo, es entendible si se tiene en cuenta la diferenciación que existe entre la poesía oral y la poesía escrita; así, en tanto que el aedo necesitaba apoyarse en versos formularios y otros recursos de composición para memorizar el relato y captar la atención de los oyentes, un poeta como Apolonio, que desarrolla su labor poética en un contexto diferente (en el que ya no predomina la oralidad, y los escritores apuntan a un público erudito y selecto), cuenta naturalmente con otros recursos compositivos y estilísticos para crear su epopeya. 
Otro rasgo en el que también a nivel formal dialoga Apolonio con Homero es el uso de los símiles, aunque si bien utiliza igualmente este recurso épico, introduce en él variaciones propias. El poeta helenístico, como se sabe, no utiliza este recurso como un procedimiento oral. Según se mencionó antes, al desarrollar su obra en un contexto diferente, Apolonio prescinde en buena medida de muchas de las más antiguas técnicas épicas (como el uso de epítetos y escenas típicas), y emplea otras (como los símiles) ateniéndose al modelo tradicional, pero otorgándoles al mismo tiempo una nueva funcionalidad.

Como algunos críticos (entre ellos Gil Fernández, 2007, pp. 247-251) ya han notado, Apolonio se propone renovar los símiles no solo en su forma, sino también en su contenido y su función. Con respecto a la forma, Apolonio utiliza algunas de las fórmulas homéricas, pero también emplea otras que no se hallan en la obra del antiguo aedo. Sobre el aspecto de contenido, aunque toma referentes de la naturaleza para realizar las comparaciones, se observa cierto gusto por las escenas cotidianas y las emociones humanas (lo cual tampoco era ajeno a Homero, a pesar de que en él el tratamiento de estas era menor). Esto, por ejemplo, se evidencia en el encuentro de Jasón y Alcímeda (Arg., I, v.268-275).

En cuanto a la función de los símiles, es posible afirmar que Apolonio los ajusta a la narración, de modo que queden estrechamente vinculados al relato, y describan con elocuencia un rasgo de la acción referida, un estado anímico, o el ambiente en el que se desarrolla un hecho determinado. Así se aprecia, por ejemplo, en símiles como el que hace alusión a la partida de los Argonautas de la costa de Págasas, en donde se combinan diferentes elementos sensoriales para referir el modo en que la tripulación se aleja remando del puerto (Arg., I, v.536546). Se puede asegurar también que Apolonio se acerca bastante al lenguaje homérico en algunos de sus símiles, aunque introduce variantes propias ${ }^{6}$.

Por otro lado, en el transcurso del libro I de Las Argonáuticas se aprecia que los diferentes episodios que se presentan a lo largo del recorrido de los Argonautas tienen sus paralelos correspondientes en pasajes sobre todo de la Odisea, pues están estructurados siguiendo el modelo del relato de aventuras marítimas. Así, la primera estancia de los Argonautas en tierra ocurre cuando estos llegan a la isla de Lemnos (Arg., I, v.607-910), episodio que recuerda la llegada de Odiseo y sus compañeros a la isla de Circe, en el canto X de la Odisea (v.135-575). La estancia en Lemnos también puede asociarse con el pasaje de Calipso (deidad que intenta retener a Odiseo en su isla, impidiéndole el regreso a Ítaca: Od., V, v.55-265) e incluso con la escena en la que Alcínoo ofrece a Odiseo la mano de su hija (Od., VII, v.309-318), pues de la misma manera Hipsípila ofrece a Jasón el trono de Lemnos, lo cual constituye un peligro para el cumplimiento de su misión.

De la misma manera que Circe, y también en cierta medida Calipso y Nausícaa, fue tentación que Odiseo debió rechazar para lograr llegar a Ítaca, Hipsípila y las mujeres lemnias son obstáculos que Jasón y los Argonautas deben sortear para cumplir su misión. Por otra parte, este pasaje constituye una anticipación del encuentro de Medea y Jasón, y de la suerte de la propia Medea, quien, como es harto conocido por la tragedia de Eurípides quien inmortalizó a este personaje, será abandonada por Jasón del mismo modo en que este abandonó a la reina de Lemnos. Incluso, la traición de los lemnios y la venganza que llevan a cabo sus mujeres no solo contra ellos sino también contra sus hijos, preludia el desarrollo posterior de la historia de Jasón y Medea, la cual concluye, como se conoce por la tragedia euripídea, con el asesinato por parte de Medea de sus propios hijos a causa de la deslealtad del Esónida.

En el momento en el que Jasón se prepara para su encuentro con Hipsípila se describe un manto que Atenea regaló al héroe, lo cual remite a la écfrasis del escudo de Aquiles en el canto XVIII de la Ilíada (v.478-608) y a la del manto de Odiseo en el canto XIX de la Odisea (v.224-235). Las descripciones de estos objetos se asemejan en cuanto a las características de opulencia y resplandor que se les atribuyen, así como al carácter cinematográfico de las figuras representadas. Carla Bochetti (2006) sostiene que en estos objetos: "Homero no trata de representar eventos particulares, sino paradigmas continuos de las actividades

6 Sobre el uso del lenguaje homérico en Las Argonáuticas, cf. Seaton, R. C. (1891, pp. 1-13). 
humanas y sociales" (p. 117), y que la écfrasis homérica se encuentra también vinculada con otros momentos del relato. En el escudo de Aquiles, por ejemplo, se observaban dos ciudades, una en tiempo de paz y otra en tiempo de guerra, y se veían además escenas relacionadas con la naturaleza y la vida campestre (una vendimia, el trabajo de los pastores, las danzas de los jóvenes, etcétera); en el manto de Odiseo, por otra parte, se encontraba bordado un episodio de caza, en el que un perro perseguía a un cervatillo. Esas escenas asociadas con la naturaleza y con acciones de la vida cotidiana (como la cacería, la labranza, etcétera) ciertamente pueden conectarse con muchas de las imágenes presentadas por el poeta en los símiles que aparecen en otros pasajes de su narración.

En el manto de Jasón, por otro lado, se muestran diversas escenas mitológicas (Arg., I, v.721-767). En todas ellas resaltan los contrastes empleados por el poeta: en la primera aparecen los cíclopes forjando el rayo de Zeus; en la segunda, que representa la construcción de Tebas por Anfión y Zeto, se destaca la oposición entre estos hermanos: este último con su enorme fuerza física contrasta con el primero, quien posee el mágico don de la música; en la tercera escena aparece la delicada Afrodita sosteniendo el escudo de bronce de Ares, mientras su imagen se ve reflejada en el mismo; la cuarta refleja el combate entre los teléboas y los hijos de Electrión a causa de un rebaño de vacas ${ }^{8}$; la quinta representación corresponde a la competencia de carros entre Pélope y Enómao9; en la penúltima escena aparece el joven Febo disparando su arco contra el gigante Ticio, quien había intentado agredir a Leto; y la última parte del manto presenta a Frixo hablando con el carnero mágico, lo cual remite directamente al mito que da origen a la saga de los Argonautas. Al igual que las écfrasis homéricas, la descripción de Apolonio de este manto tiene un carácter cinematográfico, pues se enfatiza en ella el movimiento de las figuras, y los episodios representados están además estrechamente vinculados con el marco general del poema. En suma, como afirma Clauss (1993), con las escenas del manto de Jasón: "Apollonius provides a symbolic representation of the expedition” (p. 128).

De esta manera, es posible percibir que esos contrastes que se evidencian en la écfrasis podrían corresponderse con la caracterización del propio Jasón, nuevo tipo de héroe, que saldrá victorioso de su empresa, no por el empleo de su fuerza física o su capacidad guerrera, como el antiguo héroe homérico, sino por su astucia y sus dotes amatorios, como ya se preludia con la figura de Afrodita portando el escudo del dios de la guerra, y con el propio episodio de Jasón e Hipsípila. Es por esto también que esta parte del poema funciona como un resumen autotextual o mise en abyme $e^{10}$, que anticipa la llegada de Jasón a la Cólquide.

Esta idea se ve reafirmada por los símiles con los que el poeta caracteriza al Esónida. En primer lugar, lo compara con Apolo (Arg., I, v.307-310) y luego con el lucero vespertino, cuando marcha a encontrarse con Hipsípila (Arg., I, v.774-781). Finalmente, ya en el libro III, cuando Jasón va al encuentro de Medea es comparado con Sirio (v.956-961). Una comparación similar se encuentra en el canto XXII de la Ilíada, referida a Aquiles (v.2531). Nuevamente se tiene un contraste entre Aquiles y Jasón, en aquel se resalta el valor guerrero (se describe su escudo, su marcha hacia el combate) y en Jasón su carácter cortesano (se habla de su manto, de su atractivo físico, del modo en que se dispone a ir al encuentro de la doncella). Los símiles marcan la oposición entre los dos héroes, y permiten percatarse de que de la misma manera en que Aquiles era funesto en el combate, Jasón lo es en las lides amorosas.

\footnotetext{
$7 \quad$ Clauss (1993) halla en esta escena ecos de aquella otra que aparece en la Ilíada, en la cual Hefesto se encuentra trabajando en su forja en el momento en el que Tetis llega a pedirle que fabrique una nueva armadura para Aquiles.

8 Según una versión de este mito, los teléboas eran descendientes de Perseo y Andrómeda, y habían marchado a Micenas para pedir su herencia (el ganado) a Electrión. De este modo, podría detectarse una semejanza entre este pasaje y el propio mito de los Argonautas, quienes marchan a la Cólquide para recuperar el vellocino de oro que perteneció a Frixo, antepasado de Jasón. Ver Clauss, J. (1993).

9 Este mito anticipa las pruebas a las que se enfrentará Jasón en la Cólquide.

10 Sobre este concepto, véase Dällenbach, L. (1997, pp. 89-93).
} 
Volviendo al libro I, se aprecia un segundo episodio, luego del referido a Lemnos. Se trata esta vez de la llegada de los Argonautas al país de los dolíones (v.948-1078), quienes eran gobernados por Cícico. Ha sido apuntada en ocasiones la relación que guarda este pasaje con el relatado en el canto IX de la Odisea (v.39-61), que se refiere al enfrentamiento de Odiseo y sus compañeros con los cícones. Como se narra en ese canto, el héroe y sus hombres combaten con a estos adversarios y los vencen, pero, confiados, permanecen en el país de estos en lugar de partir, por lo que la tribu va en busca de ayuda y contraatacan, causándoles grandes daños a los aqueos.

De manera similar, aunque con sentido opuesto, Jasón y los Argonautas son recibidos hospitalariamente por los dolíones y Cícico, y se marchan de esa tierra sin contratiempos. Pero en la noche son arrastrados hacia atrás por los vientos y desembarcan nuevamente en el país de los dolíones sin percatarse de ello. Los pobladores tampoco reconocen a los Argonautas y entablan una cruenta batalla contra ellos. Los combates individuales de los héroes, aquí descritos, recuerdan los de la Ilíada, aunque son referidos de forma más sintética. Por otro lado, este episodio también puede ser relacionado con el de Eolo (Od., X, v.1-78), quien recibe hospitalariamente a Odiseo y sus compañeros cuando estos llegan por primera vez a su isla, y los ayuda a reanudar su viaje, pero al arribar la nave de los aqueos de nuevo a su territorio, los expulsa de allí.

El libro II es una continuación del primero, pues contiene el resto de los episodios que integran el viaje de la Argo hasta arribar a la Cólquide. En un primer momento se alude a la estancia de los Minios en el país de los bebrices (v.1-164), cuyo equivalente es la aventura de Odiseo en el país de los cíclopes, relatada en el canto IX de la Odisea (v.180-543). Al igual que estos, Ámico y su pueblo representan la barbarie, ya que no respetan las leyes de la hospitalidad y reciben rudamente a los extranjeros; Odiseo y Jasón, en cambio, manifiestan un comportamiento civilizado. Este contraste se evidencia asimismo en el enfrentamiento de Ámico y Pólux, quien acepta el desafío hecho por el insolente rey de los bebrices. Desde el inicio, el poeta caracteriza de modo contrapuesto a ambos contendientes.
Las descripciones de pugilatos eran ya conocidas en la épica anterior. Así, por ejemplo, aparecen en el canto XXIII (v.685-694) de la Ilíada, cuando se enfrentan Epeo y Euríalo en los juegos fúnebres en honor de Patroclo, y en el canto XVIII (v.95-100) de la Odisea, cuando Odiseo lucha con el mendigo Iro. Apolonio recrea el duelo pugilístico con una gran semejanza a sus antecedentes épicos. Esto se revela en el uso de los símiles y en la precisión con que se definen los cambios fisiológicos que experimentan los personajes mientras luchan. La batalla que libran los Argonautas contra los bebrices (v.99-135), luego de la muerte de Ámico a manos de Pólux, es también muy fiel al modelo homérico, sobre todo por los símiles y las descripciones anatómicas de las heridas recibidas en el combate.

Luego de salir del país de los bebrices, los Argonautas se dirigen a la tierra de Tinia, en la que se encuentran con el adivino Fineo, quien les profetiza una parte de lo que ocurrirá en el resto de su travesía y los aconseja para que lleguen airosos a su destino (Arg., II, v.178-448). La anticipación que hace Fineo a través de su predicción es equivalente a la hecha por Tiresias a Odiseo en el canto XI (v.92-137), y también a la de Circe en el canto XII (v.37-141) de la Odisea. El paso de las Simplégades (Arg., II, v.549605), por otra parte, preludia el pasaje del libro IV en el que la Argo atraviesa las Rocas Planctas, el cual aparece asimismo en el canto XII de la Odisea (v.234-259).

El libro III es el que más se aparta del paradigma homérico, pues tiene una filiación más marcada con la tragedia y manifiesta con mayor amplitud rasgos propiamente helenísticos. No obstante, se hallan en él algunos pasajes que tienen un referente explícito en las obras de Homero. Así, se tiene un primer episodio divino que se corresponde con las escenas olímpicas del canto XVIII (v.368-467) y, sobre todo, del canto XIV (v.187-223) de la Ilíada, y que recuerda además las asambleas de los dioses homéricos. La escena olímpica de Las Argonáuticas (v.10-110) tiene, sin embargo, un carácter peculiar. Hera y Atenea van en busca de Afrodita para solicitar su ayuda, pues Jasón necesitará del amor de Medea para vencer las pruebas de Eetes y obtener el vellocino de oro. Una vez más se evidencia el paralelo y el contraste con el antiguo paradigma heroico, la contraposición entre Aquiles y 
Jasón se convierte en un leitmotiv; Tetis ha pedido a Hefesto armas para el combate, y Hera ha ido a pedir a Afrodita (como ya lo había hecho en la Ilíada) armas para el amor. La manera en que se desarrolla el encuentro entre las tres diosas pone de manifiesto rasgos típicamente helenísticos. Las deidades se han humanizado mucho más y se presentan en un contexto cotidiano; a la llegada de Hera y Atenea, Afrodita se encuentra sentada en un sillón delante de la puerta de su morada, y peina sus cabellos. Cipris las recibe con agrado, aunque también con cierta ironía (Arg., III, v.52-54).

Por otra parte, la llegada de Jasón y sus acompañantes a la ciudad de los colcos (Arg., III, v.197-251) se inspira en el arribo de Odiseo al país de los feacios en el canto VII (v.14-132) de la Odisea. Hera esparce niebla por la ciudad para que el joven pase desapercibido a la vista de los colcos, como había hecho Atenea al envolver en una nube a Odiseo para que no fuese visto por los feacios. Son similares las descripciones de los palacios, que se delinean con belleza y suntuosidad, aunque, como explica Hughes Fowler (1989, p. 171), la descripción del palacio de Eetes es más realista desde el punto de vista arquitectónico y visual.

El motivo del sueño es otro de los elementos que toma Apolonio del epos homérico, pero al que da sin embargo un matiz propio. Como bien se afirma en Introducción a Homero, el aedo:

concibe al sueño (匹rvos) no como un estado psicofisiológico del sujeto, sino como algo externo, objetivo, casi material que viene sobre el hombre [...] En esta misteriosa situación le visitan los ensueños (ฟદıрoเ), que, asimismo, tienen una existencia exterior objetiva e independiente de su actividad mental. (Rodríguez Adrados et al., 1963, p. 421)

Un ejemplo de estos ensueños se observa en el canto II de la Ilíada (v.1-47), cuando Zeus envía al Sueño a dar un mensaje a Agamenón. El Sueño se coloca sobre la cabeza del rey, que estaba dormido, y, transfigurándose en Néstor, le comunica la voluntad de Zeus. Como sostiene Fernández Contreras (2002), este motivo del "sueño como visita sobrenatural" (pp. 9-37) es uno de los medios mediante los cuales las deidades intervienen en el mundo de los mortales. Así, en múltiples ocasiones los propios dioses toman la forma de alguien conocido para visitar en sueños a los hombres, o crean un $\varepsilon \Phi \omega \lambda$ ov para que les hable (este es el caso de Atenea en el canto IV de la Odisea, v.793-842, cuando envía un "fantasma" con la forma de Iftima, hermana de Penélope, para consolar a esta). En muchos casos, estas intervenciones divinas tienen como objetivo exhortar a los personajes a llevar a cabo una determinada acción.

Otros sueños, como el que es tenido por Penélope en el canto XIX de la Odisea (v.535-553), poseen un carácter premonitorio. En este aparece un águila que da muerte a unos gansos, lo cual, como se explica claramente, constituye una anticipación del fin que tendrán los pretendientes a manos de Odiseo. En el canto XX (v.8490), por otra parte, Penélope da a conocer mediante un monólogo otro sueño que ha tenido, en el cual dormía a su lado un "fantasma" semejante a Odiseo. Este tipo de sueños homéricos que no solo son provocados por una divinidad, sino que también dependen en cierta medida del estado psicológico del sujeto que sueña (Fernández Contreras, 2002, p. 20), se encuentran mucho más cercanos a las situaciones oníricas recreadas por el poeta helenístico.

En Apolonio, en efecto, a diferencia de Homero, los estados del sueño y del ensueño no se corporeizan, no se convierten en una realidad material y externa al sujeto que duerme, sino que son una experiencia interior de dicho sujeto, una manifestación de su subconsciente, que refleja las emociones o deseos de este. Es precisamente una manifestación del subconsciente lo que surge en Medea, luego de haber sido flechada por Eros al ver a Jasón. Cuando se queda sola en sus aposentos se debate con los sentimientos encontrados que experimenta. En medio de sus reflexiones se apodera de ella el sueño, $y$, según se expone en este momento, "un ensueño engañoso (como de quien mucho sufre) y aciago vino a turbarla" (Arg., III, v.618-619). En este sentido, el sueño de Medea se asemeja al de Penélope en el canto IV de la Odisea, pues la esposa del Laertíada se duerme luego de pensar en si su hijo escaparía de la trampa que le preparaban 
los pretendientes, por lo que el contenido del sueño está directamente relacionado con los pensamientos que cavilaba durante su estado de vigilia. Sin embargo, el sueño de Medea no es ocasionado por los dioses ni viene a ella en la forma de un $\varepsilon \delta \omega \lambda$ ov, sino que es provocado por el propio inconsciente de la joven.

Así, Medea siente en su sueño que Jasón no se somete a las pruebas de Eetes para llevarse el vellocino, sino que ha venido a la Cólquide para tomarla por esposa (v.619-633). Le parece que es ella misma la que vence las pruebas impuestas por su padre y decide marcharse con el extranjero, traicionando a los suyos. Como se puede apreciar, el ensueño de Medea tiene una base puramente psicológica, pues se corresponde a cabalidad con los sentimientos de la joven y anticipa asimismo la actitud que ella adoptará, al ayudar a los Argonautas a llevar a término su empresa, y asumir además un papel protagónico en la consecución de esta. Se puede afirmar que este sueño vale para aclarar los sentimientos de Medea con respecto a Jasón y para complementar su caracterización como personaje.

La entrevista de Jasón y Medea (Arg., III, v.957-1149), por otro lado, es similar a la de Odiseo y Nausícaa en el canto VI de la Odisea (v.141-316). Ambas doncellas salen al amanecer acompañadas de sus sirvientas, y se dirigen al encuentro de un extranjero que requerirá su auxilio. Se hace asimismo notable la semejanza existente entre Odiseo y Jasón en cuanto a la atracción que ejercen en las mujeres por su apariencia; de la misma manera en que Atenea infunde gracia a Odiseo cuando este se presenta ante Nausícaa y Penélope (Od., VI, v.228-234; Od., XXIII, v.153-165), Jasón aparece ante Hipsípila y Medea semejante a un astro refulgente (Arg., I, v.775-782; Arg., III, v.957960). Tanto Odiseo, el héroe de "multiforme ingenio"1, como Jasón, el nuevo paradigma de héroe cortesano, manejan a la perfección las estrategias del discurso, y saben cómo convencer a sus oyentes y obtener el favor que imploran. Para persuadir a Medea, Jasón le dice que será compensada por su ayuda y honrada por todos los helenos (incluso llega a proponerle matrimonio), y alude a la historia de Teseo y Ariadna (Arg., III, v.997-1004).
Como es evidente, este mito guarda un parecido innegable con el de Jasón y Medea. La traición de Teseo a Ariadna anticipa la que habrá de hacer Jasón a Medea. Ambas doncellas, emparentadas además por ser descendientes de los hijos de Helios, traicionan a sus padres para luego ser traicionadas por el hombre al que han ayudado. El paralelismo se repite con más intensidad en el libro IV (v.421-434), cuando Medea y Jasón envían regalos de hospitalidad a Apsirto para atraerlo a una trampa y darle muerte. Entre estos obsequios se encontraba el manto regalado por Hipsípila a Jasón en el momento de su partida; este manto había pertenecido a Dioniso, quien había yacido en él junto a Ariadna (pues, cuando la joven fue abandonada por Teseo en Naxos, el dios la desposó en este lugar). El simbolismo portado por este objeto se hace entonces patente: Medea se dispone a traicionar completamente a su familia, al tramar el asesinato de su propio hermano, y, sin embargo, ella también, al igual que Ariadna, será víctima de una traición. De esta forma, con el motivo del manto, se repite la anticipación del destino de Medea que ya se anunciaba desde la escena de Lemnos.

La crítica (Easterling y Knox, 1990, pp. 640-641) ha hallado asimismo una conexión entre este episodio y el catálogo de mujeres que se presenta en el canto XI (v.235328) de la Odisea. En efecto, en su descenso a los Infiernos, Odiseo ve a mujeres de ilustre linaje que fueron esposas de héroes o de dioses. Las historias de estas mujeres también están en gran medida signadas por el engaño y la traición, y resulta ciertamente interesante el hecho de que el catálogo comience haciendo alusión a Tiro, quien, seducida dolosamente por Poseidón, dio a luz a Pelias y a Neleo (y luego tuvo de Creteo otros hijos, entre ellos a Esón), y termine refiriéndose a las hijas de Minos, Fedra y Ariadna. De haber tenido en cuenta Apolonio estos referentes para crear el pasaje al que se alude aquí, lo cual es sumamente probable pues ya se ha comprobado su dominio del modelo épico con el que dialoga y su gran erudición, se hace visible la complejidad que presenta Las Argonáuticas, por la complicada trama de símbolos y de veladas alusiones que se van estableciendo en el transcurso de la obra.

11 Este es uno de los principales epítetos de Odiseo. Se toma en este caso la traducción de Luis Segalá y Estalella. 


\subsection{Transposiciones}

Es precisamente en el libro IV en el que se hallan de manera más marcada transposiciones directas de la acción de las epopeyas homéricas a Las Argonáuticas de Apolonio. Este momento de la obra está notablemente vinculado al canto XII de la Odisea, puesto que una parte significativa del viaje de regreso de los Argonautas se corresponde con la ruta seguida por Odiseo en su vóøtos. Apolonio transpone en efecto una parte del periplo odiseico a la acción de Las Argonáuticas, pero no de un modo meramente imitativo, sino otorgándole una significación diferente.

A pesar de que el camino tomado por los Minios para regresar a Yolcos es mucho más extenso que el que siguieron para arribar a la Cólquide, es narrado de manera mucho más concentrada y sintética. Cuando, luego de un extenso periplo, la tripulación penetra en el curso del Ródano, el poeta refiere que este río procede "del punto más remoto de la tierra, donde están las puertas y los cimientos de la Noche” (Arg., IV, v.627-633). Esta referencia recuerda la llegada de Odiseo y sus compañeros al Hades en el canto XI de la Odisea (v.13-19). Los Argonautas, sin embargo, no hacen escala en este lugar, sino que continúan su trayecto. Así, se hace notable en Las Argonáuticas la ausencia de una vékuı $\alpha$ igual a la que aparece en la Odisea.

Luego del paso por la tierra de los celtas, los tripulantes de la Argo transitan por las Islas Estécadas y por la isla de Etalia, para finalmente arribar a la costa de Eea, hogar de Circe (Arg., IV, v.660-664). Así, el episodio de Circe es, como se puede apreciar, recreado de dos maneras: primeramente se alude de modo indirecto en el pasaje de Lemnos, y luego se presenta de modo directo y explícito en este momento de la obra. Asimismo, tanto en este pasaje como en los siguientes, que se encuentran basados en la ruta odiseica, aparece lo que Broich (2004) define como "forma particularmente extrema de marcación de la intertextualidad" (p. 96), pues se presentan en ellos figuras literarias propias de los textos homéricos, aunque en este punto es válido aclarar que la presencia común de estos personajes en las obras de ambos poetas se justifica sobre todo a causa de que forman parte del conjunto de mitos griegos que los dos adoptan de la tradición.

Tal como aparece en el canto X (v.210-220) de la Odisea, en la obra alejandrina la hechicera está rodeada por sus monstruosas criaturas. En Las Argonáuticas estos seres no poseen formas propiamente animales como en la Odisea, donde aparecían transformados en lobos y leones, sino que tienen mezclados miembros humanos y animales, con lo cual se evidencia cierto gusto por lo grotesco, presente en la estética del helenismo.

El recibimiento de Circe a los viajeros es también diferente. La hallan purificándose a orillas del mar, temerosa por un sueño que ha tenido, en el cual las paredes de su casa goteaban sangre y todo era devorado por las llamas. Se está en presencia aquí de otro sueño de carácter premonitorio y alegórico, como el de Medea, que recuerda también los sueños de Penélope en la Odisea. Resulta interesante una observación realizada por Fernández Contreras (2002, p. 28), con la cual hace notar que la Circe de Apolonio contrasta con la Circe homérica, en cuanto a la precaución que toma ante las señales que se le manifiestan. Mientras que en el canto X de la Odisea la hechicera se percata demasiado tarde de la identidad de Odiseo, cuya llegada le había sido ya avisada por Hermes, la Circe de Apolonio toma prontas prevenciones ante el presagio que se le ha presentado.

Circe invita a los extranjeros a su morada, posiblemente con el propósito de hechizarlos como había hecho con sus huéspedes anteriores (y como lo hará luego con la tripulación de Odiseo), pero solo la siguen Jasón y Medea. Circe los purifica con el sacrificio de los suplicantes que han cometido un crimen, pero, al conocer el origen de Medea y su falta, los expulsa de su casa. A pesar de esto, es posible notar que, frente a la figura de pérfida hechicera que se delinea en la Odisea, la Circe de Apolonio se encuentra más humanizada, puesto que no solo respeta a los huéspedes que han llegado ante ella como suplicantes, sino que se compadece de Medea por la suerte que correrá y por ser de su propio linaje (v.739-753). 
Los Argonautas parten de la isla de Eea, y con el auxilio de los dioses consiguen salir ilesos de los próximos peligros del viaje. Primeramente transitan junto a la isla Antemóesa, en la que habitaban las Sirenas. Del mismo modo en que tentaron a Odiseo, las Sirenas pretenden atraer a los Argonautas para hacerlos perecer, pero Orfeo derrota con su lira la voz de las doncellas (v.891-920). A continuación, la Argo se encuentra entre las Rocas Planctas, y el estrecho de Escila y Caribdis. Odiseo se había visto forzado a pasar con sus compañeros por este terrible estrecho, teniendo a un lado el escollo de Escila, monstruo que devoraba a quienes se le aproximasen, y del otro lado el escollo de Caribdis, quien absorbía terriblemente el agua y la volvía a echar fuera (Od., XII, v.234-259). Jasón y los Argonautas son sin embargo salvados por el favor de Hera; la Argo es transportada por Tetis y las Nereidas lejos del fatal estrecho, a través de las Planctas (v.920-963). De este sitio los navegantes se dirigen hacia la pradera de Trinacria, donde pacían las vacas de Helios, causantes asimismo de numerosos males para Odiseo y su tripulación. Con una breve descripción del rebaño sagrado y la alusión a las hijas de Helios, Faetusa y Lampecia (personajes también presentes en la Odisea), quienes estaban encargadas de custodiar las reses, el poeta pasa a la próxima escena (v.968-982).

Para completar el periplo odiseico, los héroes arriban a la isla de los feacios (canto VI de la Odisea), llamada en Las Argonáuticas Drépane (la cual se identifica con la Esqueria homérica). Este pasaje, al igual que el de Circe, se ve articulado en dos niveles diferentes dentro de la narración principal: primeramente se alude de manera simbólica en el episodio de los mariandinos, quienes reciben hospitalariamente a los Argonautas (como lo hicieron los feacios con Odiseo), y luego se refiere de forma directa, al insertarse en el relato el lugar real (la isla de los feacios) que había sido presentado con anterioridad en la Odisea. Aquí los Argonautas son recibidos con hospitalidad por Alcínoo, pero son alcanzados por una parte de las tropas de los colcos, que aún los perseguían. Medea suplica la protección de la reina Arete (como también lo hace Odiseo), y esta intercede ante Alcínoo a favor de la joven (v.993-1123).
Destaca en este episodio el carácter cotidiano, tan del gusto helenístico, del coloquio entre Arete y Alcínoo, el cual se desarrolla en el lecho de ambos esposos ${ }^{12}$. En la transformación que realiza Apolonio de este pasaje homérico, algunos autores han hecho incluso lecturas políticas con respecto al contexto en el que se inserta la obra. Así, por ejemplo, Mori (2001) sostiene que:

The Homeric Arete publicly defends Odysseus, whereas in the Argonautica Arete helps Medea by speaking privately to Alcinous. In addition, Apollonius expands Alcinous' administrative role. The Homeric Alcinous governs with thirteen other rulers (basileis), but in the Argonautica Alcinous governs Phaeacia independently. It might therefore appear that Alcinous becomes more dominant in the later epic as Arete simultaneously becomes less authoritative, speaking privately to the king rather than before the assembled Phaeacians [...] By eliminating the Homeric council and streamlining the Phaeacian government, Apollonius simulates the Ptolemaic monarchy. Apollonius' reconfiguration of Arete's role is especially intriguing in light of the controversy over the influence of Arsinoë II Philadelphus. (p. 88)

El rey de los feacios decide entregar a la doncella a los colcos si esta aún no se había unido a Jasón, por lo que los jóvenes deben casarse cuanto antes. El contraste que se percibe en esta escena, en la que los amantes celebran sus bodas, temerosos al mismo tiempo del ataque de los colcos, anuncia también en cierta medida el carácter infausto que ha de tener su unión (v.11281169). La expedición debe hacer aún otras escalas antes de llegar a su destino, pero estos pasajes ya no tienen correspondientes en las aventuras marítimas de Odiseo.

\section{Conclusiones}

A través del análisis del diálogo intertextual que se establece entre Las Argonáuticas de Apolonio de Rodas y las epopeyas de Homero, se ha podido apreciar que el poeta helenístico conjuga en su obra elementos de

12 Cf. Körte, A. y Händel, P. (1973, p. 154). 
innovación y de tradición. Se concluye que el alejandrino entabla un diálogo creativo con sus modelos épicos, pues, aunque adopta muchas de las normas instituidas por la tradición, renueva otros aspectos al incorporar presupuestos diferentes, que se encuentran no solo en correspondencia con su tiempo, sino también con su propia sensibilidad poética.

Así, a pesar de la polémica literaria que en ocasiones situó a Apolonio de Rodas en oposición a Calímaco de Cirene (otro de los escritores cimeros de la poesía alejandrina), a causa de su elección de componer un poema de relativa extensión, haciendo frente a los cánones estéticos que imperaban en su época, es posible sostener que no existió un antagonismo absoluto entre las posturas adoptadas por ambos autores. Mediante el análisis realizado se pudo comprobar que Apolonio no fue un simple cultor de la épica posthomérica criticada por Calímaco, sino que fue capaz de introducir significativas innovaciones en su obra frente a los aspectos heredados de la tradición literaria anterior. De este modo, al mismo tiempo que se nutrió de esta, incorporó a su poema rasgos propiamente helenísticos, como el uso de la ironía y el humor, el gusto por la erudición y el interés por los detalles etiológicos, el tratamiento del tema amoroso, la representación de escenas cotidianas, así como el intento de crear, en muchas de las descripciones empleadas por él, los efectos artísticos (principalmente pictóricos) presentes en las artes del período. En cuanto a las características formales, se destacan en Apolonio la reelaboración en sentido general de motivos tomados del epos homérico (como el motivo de los sueños, los símiles, el catálogo heroico, los epítetos, las escenas típicas, etcétera), el principio de variación que introduce en su obra, su elección de la estructura en episodios (a manera de epilios) para conformar la trama del poema, y su preferencia por la economía verbal.

De esta forma, la intertextualidad que Apolonio establece con Homero está determinada sobre todo por los nuevos aportes que él realiza frente a la tradición. La nueva manera en que el autor aborda la épica ha hecho incluso plantear a algunos críticos, como Gil Fernández (2007), que: "el poema de Apolonio está más próximo de la novela erótica alejandrina que de la epopeya heroica tradicional" (pp. 259-260).
Finalmente, se puede estimar el grado de intensidad intertextual presente en Las Argonáuticas con relación a sus antecedentes épicos. En la opinión de Pfister (2004, pp. 44-48), en una referencia intertextual pueden medirse diferentes grados de intensidad, que él clasifica en seis criterios: referencialidad, comunicatividad, autorreflexividad, estructuralidad, selectividad y dialogicidad. En el caso de Las Argonáuticas pueden apreciarse, en mayor o menor medida, tres de ellos. El primero es el de la comunicatividad (Pfister, 2004). Es posible percibir que en el poema existe una gran intensidad intertextual en este sentido, pues el autor no solo se muestra consciente de las referencias intertextuales que pone de manifiesto en su obra, y remite a ellas marcándolas en el texto (según lo planteado por Broich), sino que se puede inferir, teniendo en cuenta el público erudito al que está dirigida la literatura helenística, como el propio autor espera el reconocimiento de estas por el lector.

Con relación al criterio de la estructuralidad (Pfister, 2004, p. 46), se hace asimismo patente que Apolonio establece un intenso diálogo intertextual con su modelo, pues los poemas homéricos, fundamentalmente la Odisea, constituyen las bases estructurales sobre las que se ha constituido el poema alejandrino. Por último, atendiendo al criterio de la dialogicidad (Pfister, 2004, p. 48), puede sostenerse que en Las Argonáuticas se observa un distanciamiento del nuevo contexto que esta obra representa con respecto al antiguo contexto en el que se insertan las epopeyas de Homero. El alto grado de intertextualidad en este caso está provocado precisamente por "la tensión semántica e ideológica" existente entre ambos contextos.

De este modo, se puede juzgar que el poema épico de Apolonio de Rodas alcanza un alto grado de intensidad intertextual teniendo en cuenta los aspectos antes referidos, pues en él su autor marca de manera consciente las referencias intertextuales a las que alude otorgándoles una relevancia comunicativa, y se sirve de dichas referencias para formar un modelo estructural, además de realizar, a través de un fecundo diálogo intertextual, "un aprovechamiento distanciador de la diferencia" (Pfister, 2004, p. 48) entre el antiguo contexto de los 
textos homéricos y el ambiente de su tiempo, lo cual le permite reflexionar en diferentes niveles (político, religioso, literario, etcétera), no solo acerca del pasado, sino también acerca de su propia época.

\section{Referencias bibliográficas}

Apolonio de Rodas (2003). Las Argonáuticas (edición y traducción de Máximo Brioso Sánchez). Madrid: Ediciones Cátedra.

Bochetti, C. (2006). El espejo de las Musas. El arte de la descripción en la Ilíada y Odisea. Santiago de Chile: Centro de Estudios Griegos, Bizantinos y Neohelénicos “Fotios Malleros”, Universidad de Chile.

Broich, U. (2004). "Formas de marcación de la intertextualidad", en Navarro, Desiderio (comp.). Intertextualität 1. La teoría de la intertextualidad en Alemania. La Habana: UNEAC, Casa de las Américas, pp. 85-105.

Clauss, J. (1993). The Best of the Argonauts: The Redefinition of the Epic Hero in Book One of Apollonius' Argonautica. Berkeley: University of California Press.

Dällenbach, L. (1997). "Intertexto y autotexto", en Navarro, Desiderio (comp.). Intertextualité. Francia en el origen de un término y el desarrollo de un concepto. La Habana: UNEAC, Casa de las Américas, pp. 87-103.

Easterling, P. E. y Knox, B. M. W. (Eds.) (1990). Historia de la literatura clásica I. Literatura Griega (Cambridge University). Madrid: Editorial Gredos.

Fernández Contreras, M. (2002). "Los sueños en Homero y Apolonio de Rodas”. Habis, no. 33, pp. 9-37. Genette, G. (1997). "La literatura a la segunda potencia”, en Navarro, Desiderio (compilador y traductor). Intertextualité. Francia en el origen de un término y el desarrollo de un concepto. La Habana: Colección Criterios, UNEAC, Casa de las Américas, pp. 53-62.
Gil Fernández, L. (2007). "La épica helenística”, en Lecciones helenísticas (compilación de Silvia Aquino). México: UNAM, pp. 233-264.

Homero (1979). Ilíada (traducción de Luis Segalá y Estalella). La Habana: Editorial Pueblo y Educación.

(1970). Odisea (traducción de Luis Segalá y Estalella). La Habana: Instituto Cubano del Libro.

Hughes Fowler, B. (1989). The Hellenistic Aesthetic. Wisconsin: The University of Wisconsin Press.

Körte, A. y Händel, P. (1973). La poesía helenística. Barcelona: Editorial Labor.

Kristeva, J. (1997). “Bajtín, la palabra, el diálogo y la novela”, en Navarro, Desiderio (comp.). Intertextualité. Francia en el origen de un término y el desarrollo de un concepto. La Habana: UNEAC, Casa de las Américas, pp. 1-24.

Mori, A. (2001). "Personal favor and public influence: Arete, Arsinöe II and the Argonautica”. Oral Tradition, 16(1), pp. 85-106.

Pfister, M. (2004). "Concepciones de la intertextualidad", en Navarro, Desiderio (comp.). Intertextualität 1. La teoría de la intertextualidad en Alemania. La Habana: Casa de las Américas, UNEAC, pp. 25-49.

Rodríguez Adrados, F., Fernández-Galiano, M., Gil, L. y Lasso de la Vega, J. (1963). Introducción a Homero. Madrid: Ediciones Guadarrama.

Seaton, R. C. (1891). "On the imitation of Homer by Apollonius Rhodius”. Journal of Philology, no. 19, pp. 1-13. 